\title{
Ziprasidone in the treatment of mania in bipolar disorder
}

\section{Stephen E Nicolson' \\ Charles B Nemeroff ${ }^{2}$}

'From the Department of Psychiatry, Montefiore Medical Center, Albert Einstein College of Medicine, Bronx, NY, USA; ${ }^{2}$ From the Department of Psychiatry and Behavioral Sciences, Emory University, School of Medicine, Atlanta, GA, USA
Correspondence: Charles B Nemeroff Department of Psychiatry and Behavioral Sciences, Emory University School of Medicine, I0I Woodruff Circle, Suite 4000, Atlanta, GA 30322, USA

Tel: + I 4047278382

Fax: + I 4047273233

Email cnemero@emory.edu
Abstract: Ziprasidone is an atypical antipsychotic with a unique receptor-binding profile. Currently, ziprasidone is approved by the US Food and Drug Administration for the acute treatment of psychosis in schizophrenia and mania in bipolar disorder. When compared to certain other atypical antipsychotics, ziprasidone appears to have a relatively benign side effect profile, especially as regards metabolic effects eg, weight gain, serum lipid elevations and glucose dysregulation. Taken together, these data suggest that ziprasidone may be a first line treatment for patients with bipolar mania. However, ziprasidone is a relatively new medication for which adverse events after long-term use and/or in vulnerable patient populations must be studied. Unstudied areas of particular importance include the efficacy and safety of ziprasidone in the treatment of bipolar depression and relapse prevention of mania as, well as in the subpopulations of pregnant women, the elderly and pediatric patients. The emergence of mania in patients taking ziprasidone is another topic for further study.

Keywords: antipsychotic, bipolar disorder, mania, mood disorder, neuroleptic, ziprasidone

\section{Introduction}

There is a growing body of evidence for the use of atypical antipsychotics in the treatment of bipolar disorder both for acute mania and long-term therapy (Chengappa et al 2004; Vieta 2005; Vornik and Hirschfeld 2005). Concerns that arise with the use of antipsychotics in bipolar patients revolve around whether clinicians are exposing patients to unnecessary risks, especially for those patients without psychosis for whom other effective treatments are available. With the use of any antipsychotic medication, the development of extrapyramidal movement side effects, particularly tardive dyskinisia, is a concern. Patients receiving typical antipsychotics carry a risk of developing tardive dyskinisia of approximately $4 \%-5 \%$ per year (APA 1992). The rate of akathisia among young patients treated with conventional antipsychotic drugs is up to $90 \%$ and decreases as the age of the patients increases (Wirshing 2001). Even among 65 year olds, the rate of akathisia with typical antipsychotic medication treatment is $15 \%$ (Wirshing 2001). Evidence suggests that patients with mood disorders are more susceptible to the extrapyramidal side effects (EPS) of antipsychotics than patients with schizophrenia (Kane and Smith 1982; Mukherjee et al 1986; Nasrallah et al 1988). While the risk of developing EPS appears lower with atypical antipsychotics, little long-term treatment data have been collected to clarify the extent of the risk (Pierre 2005). The recently published Clinical Antipsychotic Trials of Intervention Effectiveness (CATIE) study revealed that the rates of EPS in patients with schizophrenia were not significantly different between patients treated with the typical antipsychotic perphenazine and the various atypical antipsychotic drugs, though patients with a history of tardive dyskinisia were not randomized to the perphenazine arm of the study (Lieberman et al 2005). 
Potential metabolic side effects must also be weighed when considering the use of antipsychotic medications. Weight gain, increase in plasma lipid concentrations and the development of type II diabetes have been associated with certain atypical antipsychotic medications (Ananth et al 2004a; Newcomer 2005). The risk of development of the full metabolic syndrome appears to be different among the members of the atypical antipsychotic drug class (Newcomer 2005). Clozapine and olanzapine have been associated with the highest rates of weight gain, obesity, glucose dysregulation, diabetes and hyperlipidemia as well as life threatening diabetic ketoacidosis (Newcomer 2005). Risperidone and quetiapine have been suggested to exhibit a moderate risk for these metabolic abnormalities, whereas ziprasidone and aripiprazole have been shown not only to have little or no effect on body weight, lipids or glucose (Newcomer 2005) but often improve these indices when patients are switched from olanzapine and risperidone (Weiden et al 2003).

Ziprasidone is an atypical antipsychotic of the benzisothiazolylpiperazine family approved by the FDA for use in the acute treatment of schizophrenia and schizoaffective disorder in February 2001. The available data, both basic pharmacology and clinical efficacy and tolerability have been comprehensively reviewed (Nemeroff et al 2005). Ziprasidone subsequently was approved by the FDA for the treatment of acute bipolar mania including mixed episodes in August 2004 (Nemeroff et al 2005). There is also some evidence that ziprasidone may be efficacious converting antidepressant non-responders to responders in patients with unipolar depression (Papakostas et al 2004), in the treatment of agitation in patients with dementia (Cole et al 2005; Greco et al 2005; Berkowitz 2003), and in the treatment of delirium (Young and Lujan 2004; Leso and Schwartz 2002). The pharmacologic profile of ziprasidone includes the following: antagonist activity at dopamine (DA) $\mathrm{D}_{2}$, serotonin $5-\mathrm{HT}_{1 \mathrm{D}}$ and $5-\mathrm{HT}_{2 \mathrm{C}}$ receptors, inverse agonist activity at serotonin $5-\mathrm{HT}_{2 \mathrm{~A}}$ receptors and agonist activity at $5-\mathrm{HT}_{1 \mathrm{~A}}$ receptors (Nemeroff et al 2005). Ziprasidone is the most potent antagonist of 5- $\mathrm{HT}_{2 \mathrm{~A}}$ receptors of the available atypical antipsychotic drugs (Schmidt et al 2001). It is also a relatively potent inhibitor of serotonin (5-HT) and norepinephrine (NE) reuptake in vitro, unique among the atypical antipsychotics (Schmidt et al 2001). Whether this effect occurs in vivo in light of ziprasidone's tight protein binding in serum remains unknown, but it is of considerable interest because these properties are shared with clinically effective antidepressants. This review focuses on the efficacy and tolerability of ziprasidone in patients with bipolar disorder.
Table I Safety and Tolerability Trial I (Keck et al 2003)

\begin{tabular}{lll}
\hline & Placebo Group & Ziprasidone Group \\
\hline Number of patients & 66 & 131 \\
Mean Age (range) & $37(19-64)$ & $39(18-66)$ \\
Bipolar Episode & $63 \% / 37 \%$ & $65 \% / 35 \%$ \\
Manic/Mixed & & \\
Baseline MRS & 26.7 & 27.0 \\
Mean reduction MRS & 7.8 & $12.4(\mathrm{p}<0.005)$ \\
Responders & $35 \%$ & $50 \%(\mathrm{p}<0.05)$ \\
Reduction in CGI severity & 0.9 & $1.3(\mathrm{p}<0.01)$ \\
Reduction in PANSS & 2.0 & $4.8(\mathrm{p}<0.001)$ \\
Discontinuation Rates & $55.7 \%$ & $46.4 \% *$ \\
Withdrawal secondary to & $4.3 \%$ & $6.4 \% *$ \\
adverse events & & \\
Adverse Events, total & $77.1 \%$ & $90.0 \% *$ \\
Somnolence & $12.9 \%$ & $37.1 \% *$ \\
Headache & $18.6 \%$ & $21.4 \% *$ \\
Dizziness & $10.0 \%$ & $22.1 \% *$ \\
Hypertonia & $2.9 \%$ & $11.4 \% *$ \\
Nausea & $10.0 \%$ & $11.4 \% *$ \\
Akathisia & $5.7 \%$ & $10.7 \% *$ \\
Mean QTc & Not reported & $11 \mathrm{msec}$ \\
\hline
\end{tabular}

*p value not provided.

Average ziprasidone dose during days $15-21: 130.1 \mathrm{mg} /$ day.

\section{Pharmacokinetics and pharmacodynamics}

Ziprasidone oral bioavailability is about $60 \%$ in healthy volunteers when taken with food, which increases absorption by more than $50 \%$. Peak plasma concentrations occur in 3.7-4.7 hours (Miceli et al 2000). The elimination halflife of oral ziprasidone given at doses of $80-120 \mathrm{mg} /$ day is approximately 10 hours, thus it is recommended that ziprasidone be taken twice daily (Patel and Keck 2006). This dosing schedule may increase the possibility of missed doses and breakthrough symptoms, though this has not been studied. Because ziprasidone half-life is longer at higher doses (Miceli et al 2000), it has been proposed that once a day dosing may be appropriate at doses greater than $120 \mathrm{mg}$ /day (Patel and Keck 2006). The safety and efficacy of once daily dosing of ziprasidone has not been studied.

\section{Efficacy Monotherapy}

\section{Acute mania}

Two 3-week double-blind, placebo-controlled trials have been conducted to determine the efficacy and tolerability of ziprasidone in patients with acute mania (see Table 1 and Table 2). Keck et al (2003) reported the results of a multicenter (21 US and 3 Brazilian) trial of 210 patients with acute mania with a primary diagnosis of Bipolar I disorder, 
Table 2 Safety and Tolerability Trial II (Potkin et al 2005)

\begin{tabular}{|c|c|c|}
\hline & Placebo Group & Ziprasidone Group \\
\hline Number of patients & 66 & 139 \\
\hline Mean Age (range) & $39(|0-7|)$ & $39(19-70)$ \\
\hline Bipolar Episode Manic/Mixed & $61 \% / 39 \%$ & $59 \% / 41 \%$ \\
\hline Baseline MRS & 26.4 & 26.2 \\
\hline Reduction in MRS & 5.6 & II.I $(\mathrm{p}<0.0 \mathrm{I})$ \\
\hline Reduction in CGI severity & 0.43 & $1.09(p \leq 0.001)$ \\
\hline Reduction in PANSS & 3.55 & $12.01(p \leq 0.01)$ \\
\hline Discontinuation Rates & $46 \%$ & $39 \% *$ \\
\hline $\begin{array}{l}\text { Treatment-related } \\
\text { discontinuation }\end{array}$ & $1.5 \%$ & $5.8 \%(p=0.20)$ \\
\hline Adverse Events, total & $67 \%$ & $78 \% *$ \\
\hline Somnolence & $6.1 \%$ & $22.3 \%(p=0.002)$ \\
\hline Headache & $7.6 \%$ & $12.2 \%(p=0.122)$ \\
\hline Extrapyramidal Syndrome & $1.5 \%$ & $10.8 \%(p=0.013)$ \\
\hline Dizziness & $1.5 \%$ & $10.1 \%(p=0.018)$ \\
\hline Akathisia & $4.5 \%$ & $9.4 \%(p=0.167)$ \\
\hline Nausea & $1.5 \%$ & $6.5 \%(p=0.094)$ \\
\hline Asthenia & $1.5 \%$ & $5.0 \% \mathrm{TK}$ \\
\hline Abdominal Pain & $7.6 \%$ & $1.4 \% \mathrm{TK}$ \\
\hline Mean Lengthening of QTc & $2.1 \mathrm{msec}$ & $10.1 \mathrm{msec}$ \\
\hline Median Weight Change & $0 \mathrm{~kg}$ & $0 \mathrm{~kg}$ \\
\hline Weight Gain $\geq 7 \%$ & $3.4 \%$ & $4.8 \% *$ \\
\hline $\begin{array}{l}\text { Mean change in total } \\
\text { cholesterol }\end{array}$ & $-\mid \mathrm{mg} / \mathrm{dL}$ & $\mathrm{Img} / \mathrm{dL}$ \\
\hline $\begin{array}{l}\text { Mean change in total } \\
\text { triglycerides }\end{array}$ & $-8 \mathrm{mg} / \mathrm{dL}$ & $-I \mathrm{mg} / \mathrm{dL}$ \\
\hline
\end{tabular}

most recent episode manic or mixed as confirmed by the Structural Clinical Interview for DSM-IV Axis I Disorders, Patient Edition (SCID-P). Patients were required to have a Mania Rating Scale (MRS) (Endicott and Spitzer 1978) score of $\geq 14$ within 12 hours of the first dose of the double-blind medication. All psychotropic medications except lorazepam, temazepam and medications to manage movement disorders were discontinued. Patients received placebo single-blind during a washout period of 1-7 days before being randomly assigned to ziprasidone treatment or placebo groups in a 2:1 ratio. Ziprasidone was initiated at $40 \mathrm{mg}$ bid on the first day, and then increased to $80 \mathrm{mg}$ bid. Doses were adjusted to in the range of 80-160 $\mathrm{mg}$ per day during the remainder of the trial based on tolerability and efficacy. Raters blinded to the patients' medications evaluated the patients using the Schedule for Affective Disorders and Schizophrenia, Change Version (SADS-C)(Endicott and Spitzer 1978), which contains the MRS, Positive and Negative Syndrome Scale (PANSS) (Kay et al 1987), investigator-rated Clinical Global Impression (CGI) severity scale (Guy 1976), investigatorrated CGI improvement scale, and Global Assessment of Functioning Scale (GAF) (Guy 1976). A difference of
5 points on the MRS was defined a priori as the minimal clinically relevant difference in endpoint values. Primary efficacy analyses were the differences on MRS and CGI severity scale scores from baseline to endpoint in the ziprasidone group compared to the placebo group on an intent-to-treat basis. The mean dose of ziprasidone during days 8 to 14 of the trial was $139.1 \mathrm{mg} /$ day and during days $15-21$, it was $130.1 \mathrm{mg} /$ day. By day 7 , the ziprasidone-treated patients showed significant improvement on all of the symptom severity scales. The ziprasidone-treated patients showed a mean reduction of 12.4 points in their MRS scores, the placebo-treated patients, a decrease of only 7.8 points. This difference, while statistically significant, did not meet the minimally clinically relevant superiority standard established a priori. By day 2 the mean change on the MRS between the two groups was statistically significant $(p<0.003)$ and this difference was maintained until the end of the 3 -week trial $(p<0.001)$. One-half of the ziprasidone-treated patients were responders (as defined by a $\geq 50 \%$ improvement of MRS) versus only $35 \%$ of the placebo-treated group $(\mathrm{p}<0.05)$. Statistically significant differences on CGI severity and improvement scales were observed by day 4 in the ziprasidone group. At endpoint, the mean CGI severity scores as compared to baseline were reduced by 1.3 in the ziprasidone-treated patients and 0.9 in the placebo-treated patients $(p<0.01)$. PANSS scores at endpoint were significantly reduced from baseline in the ziprasidone group compared to the placebo group ( 4.8 versus $2.0, p<0.001)$. GAF scores were higher at endpoint in both groups, though greater in the ziprasidone-treated patients $(15.3$ versus $8.3, p<0.005)$. Discontinuation rates were lower in the ziprasidone-treated group (46.4\%) when compared to the placebo group (55.7\%).

Patient withdrawal secondary to adverse events was $6.4 \%$ in the ziprasidone-treated group and $4.3 \%$ in the placebo group. Adverse events occurred in $90.0 \%$ of the patients receiving ziprasidone and $77.1 \%$ of those receiving placebo. The vast majority, $96 \%$ and $99 \%$, of these adverse events were rated as mild or moderate in severity in the ziprasidone and placebo groups, respectively. No serious adverse events occurred in either group. Events that occurred more often in the ziprasidone-treated group were somnolence (37.1\% versus $12.9 \%$ ), headache $(21.4 \%$ versus $18.6 \%)$, dizziness $(22.1 \%$ versus $10.0 \%)$, hypertonia $(11.4 \%$ versus $2.9 \%$ ), nausea (11.4\% versus $10.0 \%$ ) and akathisia ( $10.7 \%$ versus $5.7 \%)$. No changes in blood pressure, pulse rate or body weight were observed in either treatment group. Significant changes in laboratory values were found in less that $2 \%$ of patients in both groups. Pre- and post-treatment 
ECG data revealed a mean QTc interval prolongation of $11 \mathrm{msec}$ in the ziprasidone-treated group. No patient had a QTc interval of greater than $500 \mathrm{msec}$.

A second and similar multisite treatment trial of adult inpatients with a primary diagnosis of Bipolar I disorder, most recent episode manic or mixed was reported by Potkin et al (2005). This study utilized inclusion criteria and dosing schedules similar to those used in the Keck et al (2003) study. The patients were evaluated using the Schedule for Affective Disorders and Schizophrenia, Change Bipolar Scale (SADS-CB) (Endicott and Spitzer 1978) which included the extracted Hamilton Depression Rating Scale (HAM-D) (Endicott et al 1981) and Montgomery Asberg Depression Rating Scale (MADRS) (Montgomery and Asberg 1979) scores. The primary efficacy endpoint was mean MRS change from baseline to endpoint. A total of 206 patients were randomized. The mean ziprasidone dose was $126 \mathrm{mg} /$ day. A statistically significant difference $(\mathrm{p}<0.05)$ in mean MRS scores was noted on the second day of the study, as well as on day 21 ( $p \leq 0.01$ ). The percentage of patients classified as responders ( $\geq 50 \%$ improvement in symptom severity) was $46 \%$ in the ziprasidone group and $29 \%$ in the placebo group ( $p<0.05)$. Mean CGI severity scale scores of the ziprasidone group showed significant improvement versus the placebo group at day $2(\mathrm{p}<0.05)$ and this difference was maintained until day $21(\mathrm{p}<0.001)$. Patients in the ziprasidone group experienced greater improvements from baseline to endpoint in PANSS Total and Positive Subscales scores compared to those in the placebo group ( $\mathrm{p} \leq 0.01)$. The magnitude of the GAF score improvement in the ziprasidone group was more than twice that observed in the placebo group (15.82 versus 7.59, $\mathrm{p}<0.001$ ). Discontinuation rates were lower in the ziprasidone-treated patients (39\%) than in the placebo group (46\%). In the ziprasidone group, $6.5 \%$ dropped out because of adverse events that were considered treatment-related. Treatment-related dropouts comprised $1.5 \%$ of the placebo group. Treatment-emergent side effects were reported in $78 \%$ of ziprasidone-treated and in $67 \%$ of placebo-treated patients. Events that occurred more often in the ziprasidone-treated group were somnolence ( $22.3 \%$ versus $6.1 \%$ ), headache $(12.2 \%$ versus $7.6 \%)$, extrapyramidal syndrome (10.8\% versus $1.5 \%)$, dizziness $(10.1 \%$ versus $1.5 \%)$, akathisia ( $9.4 \%$ versus $4.5 \%)$, tremor $(7.9 \%$ versus $1.5 \%)$, nausea $(6.5 \%$ versus $1.5 \%)$, and asthenia ( $5.0 \%$ versus $1.5 \%$ ). Mean changes in blood pressure, pulse rate or body weight were not considered clinically significant in either group. Significant changes in laboratory values were found in less that $2 \%$ of patients in both groups. $21 \%$ of patients taking ziprasidone (versus $19 \%$ in the placebo group) developed

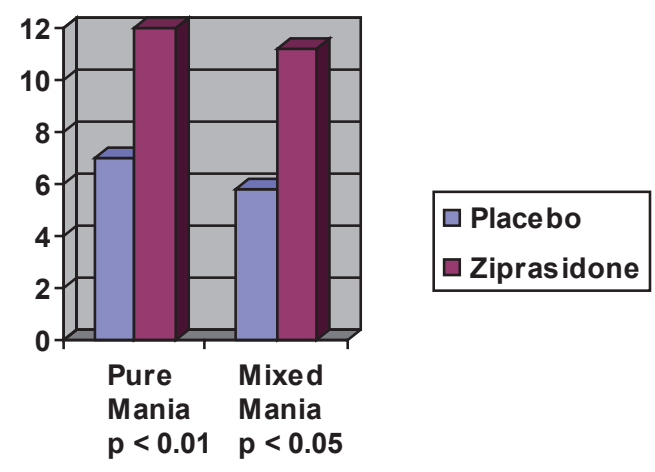

Figure I Mean decrease in MRS pure mania vs mixed episodes after 21 days (estimated from Potkin et al 2004).

elevations in triglycerides. However, the mean triglyceride level in the treatment group dropped by $1 \mathrm{mg} / \mathrm{dL}$ over the course of the trial. Electrocardiogram (ECG) evaluations revealed a mean QTc interval prolongation of $10.1 \mathrm{msec}$ in the ziprasidone-treated group versus $2.1 \mathrm{msec}$ in the placebo group. No patient had a QTc interval of greater than $480 \mathrm{msec}$. Serious adverse events were reported in 4 patients in the ziprasidone group and 1 in the placebo group, though none of these events was considered to be related to the study medication. Taken together, these results indicate that ziprasidone is effective and safe in treating acute mania.

\section{Mixed mania}

A pooled analysis of the 2 randomized, double-blind, placebo-controlled 21-day trials of ziprasidone in patients with acute bipolar mania described in detail above examined the response of patient subgroups, including those with mixed mania who were treated with ziprasidone $(n=101)$ or placebo $(n=50)$ (Potkin et al 2004) (see Figure 1). The mean decrease in MRS scores for patients with mixed mania in the ziprasidone group was significantly greater than those in the placebo group ( $\mathrm{p}<0.01$ at 14 days and $\mathrm{p}<0.05$ at 21 days).

\section{Psychotic mania}

In the pooled analysis discussed above, patients with psychotic symptoms who were in the ziprasidone treatment group $(n=116)$ had nearly double the magnitude of decrease in their MRS scores by endpoint when compared to psychotic patients who received placebo $(n=52)$ (see Figure 2$)$. This difference was statistically significant at day $4(\mathrm{p}<0.01)$ and was maintained to endpoint (Potkin et al 2004).

\section{Depression as part of mixed or pure mania}

Among patients with depressive symptoms in the Potkin et al (2005) bipolar mania trial, treatment with ziprasidone was 


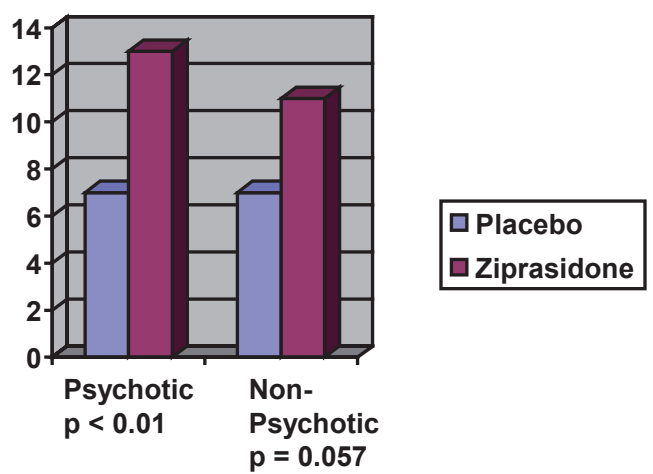

Figure 2 Decrease in MRS psychotic mania vs non-psychotic mania after 21 days (estimated from Potkin et al 2004).

associated with a mean decrease of 2.43 points on the HAM-D compared to 1.37 points in the placebo-treated patients (Potkin et al 2004; Potkin et al 2005). Mean MADRS score reduction in patients who had baseline MADRS scores of $\geq 14$ at baseline was 8.6 in the ziprasidone-treated patients $(\mathrm{n}=52)$ and $4.5(\mathrm{n}=26)$ in the placebo-treated group. Neither the difference in HAM-D or MADRS scores at endpoint, however, attained statistical significance. Another pooled analysis revealed that in patients with mixed mania and a baseline HAM-D score $\geq 14$, ziprasidone produced greater improvement $(\mathrm{p}<0.05)$ than placebo in HAM-D scores from day 2-21 (Keck et al 2004).

\section{Combination/augmentation studies}

Although monotherapy with a traditional mood stabilizer has been the recommended initial treatment for bipolar disorder (APA 2002), there is a growing body of evidence that suggests that combination therapy with a mood stabilizer and an antipsychotic medication is more efficacious, especially in cases of severe mania (Bowden 2005). The Texas Medication Algorithm Project (TMAP) also developed guidelines for treatment of Bipolar Disorder (Suppes and Dennehy 2001). The initial TMAP algorithm for mania/hypomania recommended the atypical antipsychotic, olanzapine, as an initial monotherapy option (Stage 1) along with lithium and divalproex as other options. Patients with psychotic mania who failed to fully respond to initial treatment were suggested to be then put on a combination of lithium or anticonvulsant plus an atypical antipsychotic, which could be olanzapine, risperidone, quetiapine or ziprasidone. In 2005, the algorithm was revised to include aripiprazole, risperidone, quetiapine, and ziprasidone as Stage 1a options along with lithium and divalproex (Suppes et al 2005). Olanzapine, however, was categorized, along with carbamazepine, as a Stage $1 \mathrm{~b}$ choice due to "safety and other concerns".
Weisler et al reported that the addition of ziprasidone to lithium treatment reduced time to improvement (Weisler et al 2003) (see Table 3). This 21-day, double-blind trial randomized 205 patients with Bipolar I disorder who were taking lithium and had MRS $\geq 14$ to ziprasidone or placebo. Dosage of lithium was adjusted to maintain a plasma lithium level of $0.8-1.2 \mathrm{mEq} / \mathrm{L}$. Ziprasidone was initiated at a dose of $80 \mathrm{mg}$ on day 1 and $160 \mathrm{mg}$ on day 2, with dose adjustments in the range of $80-160 \mathrm{mg}$ per day during days $3-21$. Primary efficacy variables were improvement in MRS and CGIseverity scores. By day 4 , significantly greater improvement was observed in the ziprasidone plus lithium treated patients compared to the placebo plus lithium treated patients in MRS ( 2.31 versus $1.59, \mathrm{p}<0.05)$ and CGI-severity $(2.0$ versus $0.12, \mathrm{p}<0.01)$. The significant differences in the improvements on these measures between the treatment groups disappeared by day 14 , though numerically greater improvement was maintained through the end of the study. The PANSS scores of the ziprasidone/lithium group were significantly better than those of the lithium only group on day 21 (13.4 versus $8.45, \mathrm{p}<0.01)$. This led the authors to conclude that

Table 3 Ziprasidone augmentation with lithium (Weisler et al 2003)

\begin{tabular}{|c|c|c|}
\hline & $\begin{array}{l}\text { Lithium + } \\
\text { Placebo } \\
\text { Group }\end{array}$ & $\begin{array}{l}\text { Lithium + } \\
\text { Ziprasidone } \\
\text { Group }\end{array}$ \\
\hline Number of Patients & 103 & 102 \\
\hline Mean Age in yrs (range) & $37(18-70)$ & $37(|9-7|)$ \\
\hline $\begin{array}{l}\text { Type of Manic Episode: } \\
\text { Pure/Mixed }\end{array}$ & $68 \% / 32 \%$ & $61 \% / 39 \%$ \\
\hline Discontinued & $28.2 \%$ & $30.7 \% *$ \\
\hline $\begin{array}{l}\text { Mean reduction MRS } \\
\text { (at } 4 \text { days) }\end{array}$ & 1.59 & $2.31(p<0.05)$ \\
\hline $\begin{array}{l}\text { Mean reduction MRS } \\
\text { (at I } 4 \text { days) }\end{array}$ & 5.51 & $\begin{array}{l}6.5 \text { (not statistically } \\
\text { significant) }\end{array}$ \\
\hline $\begin{array}{l}\text { Reduction in CGI severity } \\
\text { (at } 4 \text { days) }\end{array}$ & 0.12 & $2.0(p<0.01)$ \\
\hline $\begin{array}{l}\text { Reduction in PANSS } \\
\text { (at } 21 \text { days) }\end{array}$ & 8.45 & $13.4(p<0.01)$ \\
\hline $\begin{array}{l}\text { Withdrawal secondary } \\
\text { to adverse events }\end{array}$ & $4 \%$ & $8 \% *$ \\
\hline Adverse Events, total & $76 \%$ & $86 \% *$ \\
\hline Somnolence & $12 \%$ & $34 \% *$ \\
\hline Extrapyramidal Syndrome & $4 \%$ & $22 \% *$ \\
\hline Dizziness & $6 \%$ & $13 \% *$ \\
\hline Agitation & $2 \%$ & $11 \% *$ \\
\hline Abnormal Vision & $4 \%$ & $10 \% *$ \\
\hline Vomitting & $5 \%$ & $10 \% *$ \\
\hline Akathisia & $0 \%$ & $9 \% *$ \\
\hline Dystonia & $0 \%$ & $9 \% *$ \\
\hline Mean Lengthening of QTc & $6.1 \mathrm{msec}$ & $11.8 \mathrm{msec}$ \\
\hline
\end{tabular}

*p value not provided.

Average ziprasidone dose: $131.1 \mathrm{mg} /$ day. 
Table 4 Adjunctive ziprasidone with lithium 52-week open label extension (Weisler et al 2004)

\begin{tabular}{|c|c|}
\hline $\begin{array}{l}\text { Number of patients at } \\
\text { extension study baseline }\end{array}$ & $\begin{array}{l}89 \text { ( } 4 \text { I from ziprasidone }+ \\
\text { lithium, } 48 \text { from placebo + } \\
\text { lithium) }\end{array}$ \\
\hline Mean age in years (range) & $37(|8-7|)$ \\
\hline $\begin{array}{l}\text { Episode at Acute Study } \\
\text { baseline Pure Mania/Mixed }\end{array}$ & $46 \% / 54 \%$ \\
\hline $\begin{array}{l}\text { Reduction in MRS at } 52 \\
\text { weeks for those from } \\
\text { ziprasidone arm of acute } \\
\text { study }(n=10)\end{array}$ & $20.70(\mathrm{p}<0.0 \mathrm{I})$ \\
\hline $\begin{array}{l}\text { Gained } \geq 7 \% \text { of baseline } \\
\text { body weight }\end{array}$ & $12.1 \%$ \\
\hline $\begin{array}{l}\text { Lost } \geq 7 \% \text { of baseline body } \\
\text { weight }\end{array}$ & $10.6 \%$ \\
\hline Mean change in weight & -0.76 lbs $*$ \\
\hline $\begin{array}{l}\text { Mean change in serum } \\
\text { triglycerides }\end{array}$ & $-43.27(p=0.0 I)$ \\
\hline Discontinuation rate & $56 \%$ \\
\hline $\begin{array}{l}\text { Discontinuation rate due to } \\
\text { adverse events }\end{array}$ & $12.4 \%$ \\
\hline Adverse Events & $90.0 \%$ \\
\hline Somnolence & $55.1 \%$ \\
\hline Abnormal Vision & $23.6 \%$ \\
\hline Tremor & $22.5 \%$ \\
\hline EPS & $21.3 \%$ \\
\hline Dizziness & $20.2 \%$ \\
\hline
\end{tabular}

*p value not provided.

Mean ziprasidone dose at 52 weeks $(n=10): 92.6 \mathrm{mg} /$ day.

augmentation with ziprasidone helped provide rapid reduction of manic symptoms and greater improvement in overall psychopathology, although symptoms of mania were not significantly decreased by ziprasidone augmentation.

A 52-week open-label extension revealed that 89 patients treated with ziprasidone and concomitant mood stabilizers and/or antidepressants had a mean MRS score at all study visits that was significantly $(\mathrm{p}<0.01)$ improved from baseline (Weisler et al 2004) (see Table 4). The incidence of treatment-emergent side effects included: somnolence (55.1\%), abnormal vision (23.6\%), tremor (22.5), extrapyramidal syndrome $(21.3 \%)$, dizziness $(20.2 \%)$, headache $(19.1 \%)$, nausea (19.1\%), anxiety (16.9\%), insomnia (16.9\%), and akathisia (12.4\%). Simpson-Angus and Barnes Akathisia scores changed minimally. No QTc intervals over $480 \mathrm{msec}$ were recorded despite coadministration of ziprasidone with lithium. No increases in body weight or serum cholesterol levels were observed. A significant decrease in serum triglyceride levels was noted in the ziprasidone group $(\mathrm{p}=0.01)$.

Plasma lithium levels are not altered by the addition of oral ziprasidone in healthy patients (Apseloff et al 2000).
However adverse events have been reported during ziprasidone augmentation of lithium therapy. One report documented two schizoaffective patients who experienced abrupt rises in plasma lithium levels and symptoms of lithium toxicity within two days of the initiation of intramuscular ziprasidone treatment (Miodownik et al 2005).

\section{Comparison of ziprasidone with other atypical antipsychotics in acute mania}

A recent meta-analysis concluded that each of the 5 newer agents (aripiprazole, olanzapine, quetiapine, risperidone and ziprasidone) are superior to placebo in the treatment of bipolar mania and that efficacy differences between the atypical antipsychotics, if they exist, are small (Perlis 2006). Primary outcome measures were changes in the MRS or Young Mania Rating Scale (YMRS) (Young et al 1978) scores between baseline and endpoint (either day 21 or 28). Data from 12 placebo-controlled trials were evaluated, including 1881 drug-treated and 1233 placebo-treated patients. Included were at least two trials for each of the 5 atypical antipsychotic medications. No statistically significant differences were found among the medications. Two studies of each of 4 drugs (aripiprazole, olanzapine, risperidone and ziprasidone) used $50 \%$ reduction in MRS or YMRS as the criteria for response. The overall response rates for the atypicals was 53\% as compared to $30 \%$ for placebo. Ziprasidone had the highest odds ratio for response relative to placebo among the medications studied, though the difference was not statistically significant. Six add-on therapy studies were also included in the metaanalysis. Although ziprasidone showed the smallest difference between the antipsychotic/mood stabilizer treatment versus mood stabilizer monotherapy, the difference between ziprasidone and other atypical medications was not statistically significant. Because of the minimal differences in treatment effects among published trials of atypical antipsychotic medications for acute mania, the authors recommended that treatment selection be based on factors such as maintenance efficacy, tolerability, safety and cost.

\section{Maintenance studies}

A 52-week, open-label extension of a 21-day placebocontrolled trial of ziprasidone in patients with acute mania revealed sustained improvement in manic and depressive symptoms (Keck et al 2004) (see Table 5). Of the 107 patients who entered the extension, 39 remained in the study for the entire year. Only $8.7 \%$ of patients discontinued due to treatment related adverse events. The mean duration of treatment was 105 days, with the mean ziprasidone 
Table 5 Ziprasidone 52-week open label extension (Keck et al 2004)

\begin{tabular}{ll}
\hline Number of Patients & 127 \\
Mean Age in yrs (range) & $39(18-66)$ \\
Type of Manic Episode: & $69 \% / 31 \%$ \\
Pure/Mixed & \\
Discontinued & $62.2 \%$ \\
Withdrawal secondary to & $8.7 \%$ \\
adverse events & \\
Mean Change in plasma & $1.59 \mathrm{mg} / \mathrm{dl}$ \\
cholesterol & \\
Mean Change in plasma & $-14.8 \mathrm{mg} / \mathrm{dl}$ \\
triglycerides & \\
Mean Weight Change & $-2.52 \mathrm{~kg}$ \\
Weight Gain $\geq 7 \%$ & $11.0 \%$ \\
Weight Gain $\leq 7 \%$ & $11.0 \%$ \\
\hline
\end{tabular}

Mean ziprasidone dose: $122.4 \mathrm{mg} /$ day.

dose $132 \mathrm{mg}$ per day. Mean MRS and CGI-severity scores maintained statistically significant improvement over baseline scores throughout the one-year follow-up ( $<<0.0001)$. There was a reduction in mean body weight over the 52 -week period with an equal number $(11 \%)$ of patients experiencing significant ( $\geq 7 \%$ of baseline weight) weight loss and gain. Patients experienced a small $(1.59 \mathrm{mg} / \mathrm{dL})$ rise in mean plasma cholesterol levels and a moderate $(14.8 \mathrm{mg} / \mathrm{dL})$ decrease in mean plasma triglyceride levels. There was little change from baseline to endpoint in scales measuring extrapyramidal symptoms.

\section{IM ziprasidone studies}

In 2002, ziprasidone became the first atypical antipsychotic available in intramuscular (IM) form for the treatment of acute agitation in psychotic patients. In a randomized doubleblind 24 hour study which included patients with bipolar disorder or schizoaffective disorder, bipolar type, improvements in the PANSS Agitation subscale, Behavioral Activity Rating Scale (BARS) and CGI-severity scores were noted within 15 minutes of receiving the $20 \mathrm{mg}$ dose (Daniel et al 2001). In a subgroup analysis of 2 randomized, double-blind, fixed-dose, 24-hour studies of the efficacy of IM ziprasidone, patients with bipolar disorder or schizoaffective disorder, bipolar type showed improvements in the PANSS Agitation subscale, Behavioral Activity Rating Scale (BARS) and CGIseverity scores within 15 minutes of receiving the $20 \mathrm{mg}$ dose (Daniel et al 2004). The $10 \mathrm{mg}$ dose was not as effective. There was an $80 \%$ responder rate (defined by a $\geq 2$ point decrease in BARS 90 minutes after the first dose) with the $20 \mathrm{mg}$ dose, a $58 \%$ responder rate with the $10 \mathrm{mg}$ dose, and an $18.2 \%$ responder rate with the $2 \mathrm{mg}$ control dose $(\mathrm{p}<0.01)$.
Adverse events were not different in patients receiving the $2 \mathrm{mg}$ control dose compared to patients receiving the $10 \mathrm{mg}$ and $20 \mathrm{mg}$ dose. No dystonia or excessive sedation was reported in the $10 \mathrm{mg}(\mathrm{n}=20)$ and $20 \mathrm{mg}(\mathrm{n}=15)$ groups. One patient in the $10 \mathrm{mg}$ group experienced akathisia. A naturalistic study conducted on a psychiatric emergency service (Preval 2005) reported a decrease in the Behavioral Activity Rating Scale (BARS) (Swift 2002) agitation scores using $20 \mathrm{mg}$ IM ziprasidone in 110 patients with various diagnoses. Scores decreased significantly from baseline after 15 minutes $(\mathrm{p}<0.5)$ and were maintained at 2 hours $(\mathrm{p}<0.01)$. None of the patients given ziprasidone showed lasting side effects, though one patient had an acute dystonic reaction, which responded rapidly to diphenhydramine. ECGs obtained in 19 patients revealed no QTc longer than $460 \mathrm{msec}$.

\section{Pediatric bipolar disorder}

While there are no FDA-approved treatments for mania in children and adolescents, atypical antipsychotics have been used increasingly in this population (Kowatch and DelBello 2006). Barnett (2004) reported on 4 patients (ages 7-16) who successfully were switched from other medications to ziprasidone to control hypomanic and depressive symptoms and in two cases, auditory hallucinations, in the absence of other psychotic symptoms. After switching to ziprasidone these patients experienced relief of symptoms and reported a euthymic and stable mood. Each of the patients were maintained on daily doses of ziprasidone ranging from 40-80 mg per day. One patient experienced akathisia at a dose of $20 \mathrm{mg}$ tid, which completely abated after a dose reduction to $20 \mathrm{mg}$ bid.

\section{Safety and tolerability Extrapyramidal symptoms}

A flexible-dose trial in patients with schizophrenia compared the development of extrapyramidal side effects in patients taking ziprasidone (mean $116 \mathrm{mg} /$ day) and haloperidol (mean $8.6 \mathrm{mg} /$ day) (Hirsch et al 2002). Akathisia (14\% versus $16 \%$ ), hypertonia ( $2 \%$ versus $7 \%$ ), tremor ( $6 \%$ versus $10 \%)$, and extrapyramidal syndrome ( $1 \%$ versus $5 \%$ ) were all less common with ziprasidone than with haloperidol. Recent case reports have implicated ziprasidone in acute dystonic reactions in adults with schizophrenia and bipolar disorder (Mason et al 2005; Weinstein et al 2006), as well as in a child with developmental delay and attention-deficit/ hyperactivity disorder (Ramos et al 2003). There have also been several reports of tardive dyskinesia reemergence during ziprasidone treatment (Rosenquist et al 2002; Ananth, 
Burgoyne et al 2004; Mendhekar 2005) and its emergence during ziprasidone treatment (Ananth, Burgoyne et al 2004; Keck et al 2004). A recent study suggests that the frequency of movement side effects of atypical antipsychotics may be much higher (over 50\%) than those reported in clinical trials (Ghaemi et al 2006). Also of importance is that more than half of the patients enrolled in the ziprasidone trials were receiving benzodiazepines, anticholinergic or beta-blocking agents (Gentile 2007). Thus the EPS rates during ziprasidone treatment may be underestimated.

The rates of akathisia in the ziprasidone studies in acute mania have been reported at $10.7 \%$ and $9.4 \%$ (Keck et al 2003; Potkin et al 2005). In the augmentation trial with lithium, $9 \%$ of the ziprasidone-treated group reported akathisia, versus $0 \%$ in the lithium-only group (Weisler et al 2003). Akathisia rates with conventional antipsychotics have been estimated from $20 \%$ to $75 \%$ (APA 2000). Other atypical antipsychotics have also been associated with akathisia during monotherapy trials of bipolar patients, including aripiprazole $(6.5 \%-11.4 \%)$, olanzapine $(0 \%-9.6 \%)$ and quetiapine (3.6\%-5.9\%) (Gentile 2007). In short term bipolar mania trials, aripiprazole treatment was associated with akathisia in $15 \%$ of treated patients (Bristol-Myers Squibb Company 2006). The rate of akathisia with risperidone in short-term bipolar mania trials was 16\% (Janssen 2007). Antidepressant medications have been associated with akathisia (Gill et al 1997). The incidence of fluoxetine-induced akathisia is estimated between 9.8\% and 25\% (Lipinski et al 1989). The pathophysiology of akathisia is thought to be primarily due to a decrease in dopamine activity in the ventral tegmental area, a potential consequence of both the dopamine blockade by antipsychotics and of the enhanced serotinergic and noradrenergic neurotransmission by antidepressants (Catalano et al 2005). The antipsychotic and antidepressant effects of ziprasidone may both contribute to the development of akathisia in patients taking ziprasidone.

\section{Neuroleptic malignant syndrome}

Because patients treated with antipsychotic drugs are at risk for the development of neuroleptic malignant syndrome (NMS) (Keck et al 1989; Caroff and Mann 1993), physicians treating bipolar patients with atypical antipsychotic medications must be aware of this possibility. A review of NMS cases associated with the use of atypical antipsychotics revealed 68 cases in the literature, though no ziprasidone-induced NMS cases were identified (Anath et al 2004b). Since then, there have been a few cases of NMS associated with ziprasidone treatment (Murty et al 2002; Yang and McNeely 2002;
Liebold et al 2004; Gray 2004; Ozen et al 2007), as well as one case of NMS associated with the combination of lithium and ziprasidone (Borovicka et al 2006).

\section{Weight gain}

While evidence mounts that atypical antipsychotics as a class may have deleterious effects on patients' weight, ziprasidone may have an advantage by promoting less weight gain (McIntyre and Konarski 2005; Marken and Pies 2006). However the data on weight changes with ziprasidone are not conclusive. In short term studies of ziprasidone treatment have shown the risk of weight gain $\geq 7 \%$ of body weight to be as high as $10 \%$ (Sprague 2004). In a metaanalysis calculating the effects of antipsychotic medication on weight, 10 weeks of ziprasidone treatment was associated with a mean increase in weight of $0.04 \mathrm{~kg}$ (Allison et al 1999). Placebo was associated with a reduction in weight of $0.39 \mathrm{~kg}$. Other atypical antipsychotic were associated with weight gain after 10 weeks of treatment, including clozapine $(4.45 \mathrm{~kg})$, olanzapine $(4.15 \mathrm{~kg})$, and risperidone $(2.10 \mathrm{~kg})$. Studies in patients with schizophrenia treated with ziprasidone for at least 1 year have shown no effect on weight, though conclusions are limited by the small sample size (less than 400 total patients) (Gentile 2006). In patients with bipolar disorder, the data on weight change are less substantial.

\section{Cardiac adverse effects}

Since the initial clinical trials, ziprasidone has been known to prolong the QTc interval of some patients. As discussed above, in the two pivotal clinical trials demonstrating the efficacy of ziprasidone in the treatment of mania, mean QTc lengthening was reported at $11 \mathrm{msec}$ (Keck et al 2003) and $10.1 \mathrm{msec}$ (Potkin et al 2005). A report studying the effects of six antipsychotics (thioridazine, haloperidol, risperidone, olanzapine, quetiapine and ziprasidone) on QTc interval showed that none of the atypical antipsychotics studied increased the QTc by more than $16 \mathrm{msec}$ and that their use does not appear to be associated with an increased risk of cardiac events (Harrigan 2004). The mean QTc interval lengthening was $15.9 \mathrm{msec}$ for subjects taking ziprasidone. There is one case report of a patient who experienced QTc prolongation during treatment with ziprasidone associated with an asymptomatic episode of torsades de pointes (Heinrich 2006). During the treatment of this patient, on two occasions, discontinuation of ziprasidone was associated with a shortening of the QTc. As the authors note, the patient had multiple problems and was treated with other 
medications, including lithium, which has been associated with arrhythmias and QT alterations. A case series examined the effect of ziprasidone on the ECGs of 15 patients receiving above the recommended daily dose of ziprasidone (Levy et al 2004). The mean baseline QTc of these patients (including two patients already taking $160 \mathrm{mg}$ /day of ziprasidone) was $415 \mathrm{msec}$. After the patients had received at least one week of their maximum ziprasidone dose (240-320 mg/day), the mean QTc had increased to $416 \mathrm{msec}$. The maximum post treatment QTc interval was $452 \mathrm{msec}$. The authors concluded that if the study could be replicated in a double-blind placebo controlled trial, high dose ziprasidone potentially could safely be used in certain populations. Nonetheless, ziprasidone is contraindicated in patients with a history of prolonged QT, recent myocardial infarction, or uncompensated heart failure, and in patients taking medications known to prolong the QT interval (Pfizer 2007).

\section{Adverse effects-comparison with other antipsychotics}

Recent reviews on the adverse effect profiles of atypical antipsychotics indicate that ziprasidone has advantages over several of the other medications in its class, especially in the area of metabolic side effects (McIntyre and Konarski 2005; Marken and Pies 2006). The review by Marken and Pies compared the risk of adverse events with the atypical antipsychotics and haloperidol in 8 categories. Ziprasidone was classified, along with haloperidol and aripiprazole, as having the lowest risk for development of diabetes and worsening of lipid profiles. Ziprasidone and aripiprazole had the lowest risk for weight gain. The risk was rated as minor or lower with ziprasidone in the following other categories: sedation/somnolence, EPS, anticholinergic effects, orthostasis and prolactin elevation. The review by McIntyre and Konarski similarly rated ziprasidone and aripiprazole as having the lowest risk of all the atypical antipsychotics in 6 of 8 categories studied: weight gain, dyslipidemia, glucose dysregulation, myocarditis/cardiomyopathy (along with olanzapine, risperidone and quetiapine), somnolence/ sedation and prolactin (along with clozapine and quetiapine). Aripiprazole also had the lowest risk of developing QTc prolongation. Quetiapine and clozapine were rated as having the lowest risk of developing extrapyramidal symptoms.

\section{Ziprasidone-induced mania}

Manic symptom induction has been reported with atypical antipsychotics, including ziprasidone. A review of atypical antipsychotic induced mania or hypomania revealed 34 reports and 53 cases from 1994-2005 (Michalopoulou and Lykouras 2006). Of these reports there were 22 cases associated with risperidone, 14 with olanzapine, 11 with ziprasidone, 5 with quetiapine, 1 with amisulpride and none with clozapine or aripiprazole. Although the authors were unable to report the rate of medication-induced mania, it is noteworthy that at the time of the review, ziprasidone had been on the market during only 5 of the years that were studied by the authors. Clozapine and risperidone had been available during all 12 years studied, while olanzapine (10 years) and quetiapine ( 8 years) had been available for several years more than ziprasidone. The primary diagnoses of the patients in the 11 cases of ziprasidone-induced mania/hypomania were as follows: 3 patients had Bipolar I disorder, one patient had Bipolar II disorder, four had unipolar depression, two had schizophrenia and one had schizoaffective disorder, bipolar type. The dosages prescribed to the patients were in the 20-160 mg per day range with a mean dose of $76 \mathrm{mg}$ per day. The average onset from the start of treatment with ziprasidone to the induction of manic/hypomanic symptoms was 4.3 days (range 10 hours to 10 days), which was somewhat lower than the time-until-onset of symptoms with the other antipsychotics reported. Discontinuation of ziprasidone in 7 of the 11 cases resulted in successful management of mania/hypomania. In the four remaining cases, the symptoms resolved when the ziprasidone dose was lowered. Possible mechanisms of mania induction were discussed, including the 5HT-2A affinity of atypical antipsychotics. As mentioned above, ziprasidone is known to have the highest affinity for 5HT-2A receptors among the antipsychotics. The inhibition of serotonin and norepinephrine reuptake by ziprasidone, has been hypothesized as contributing to the induction of mania (Baldassano et al 2003).

\section{Special populations \\ Pregnancy}

Ziprasidone is categorized by the FDA and American Academy of Pediatrics (AAP), along with the other atypical antipsychotics (except for clozapine, which is a category B) as Pregnancy Category C (human fetal teratogenicity cannot be ruled out) (Pfizer 2005) A recent prospective study examined the effects of atypical antipsychotic medication taken by pregnant women (McKenna et al 2005). The study included 151 women treated with atypical antipsychotics in three countries. An increase in major malformations was not found, but an increased rate of low birth weight (10\% versus $2 \%, \mathrm{p}<0.05)$ was observed in babies of mothers treated 
with atypical antipsychotics. No mothers in this study were treated with ziprasidone. Little data have been gathered on the effects of ziprasidone treatment during pregnancy (Ernst and Goldberg 2002).

\section{Patients with liver disease}

Ziprasidone is metabolized by the CYP $3 \mathrm{~A} 4$ isoenzyme, but no clinically significant alterations in metabolism occur in mild-to-moderate hepatic impairment (Everson et al 2000).

\section{Ziprasidone in overdose}

As many as 1 in 5 patients with bipolar disorder will die from suicide (Isometsa et al 1994). Nearly 50\% of bipolar patients will attempt to take their own lives (Simpson and Jamison 1999). Because suicide attempts are common in patients with bipolar disorder, clinicians must be aware of the potential lethality of medications dispensed to their patients. Four cases of ziprasidone overdoses including two in combination with benzodiazepines were reported from the Pfizer-Spain database without cardiac events or abnormal QTc recordings (Gomez-Criado et al 2005). Another case of a 57-year old woman who ingested an overdose of $4440 \mathrm{mg}$ of ziprasidone recorded a maximum QTc of $457.20 \mathrm{msec} 12$ hours after the ingestion, but QTc remained under $440 \mathrm{msec}$ after 48 hours (Prieto et al 2005). Cases of ingestions as high as $12,800 \mathrm{mg}$ have been reported without significant EEG changes (Arbuck 2005).

\section{Conclusion}

In summary, ziprasidone appears to be a safe and effective option to treat bipolar disorder, especially acute mania. Ziprasidone does appear to have minimal effects on metabolic parameters, although the database of the long-term effects of ziprasidone on weight and serum lipids is limited. Initial concerns over the potential adverse cardiac effects of ziprasidone appear unwarranted. However additional investigation is needed to identify populations at risk for cardiac complications with ziprasidone. Clarification is also needed to determine the risk of EPS, especially akathisia in patients taking ziprasidone. Also needed are further studies in bipolar depression and maintenance therapy to prevent the recurrence of mood episodes. As a relatively new medication, the use of ziprasidone in special populations such as pregnant patients, children or the elderly has not been well studied. The potential of ziprasidone to cause treatment-emergent mania warrants investigation. Establishing the safety and efficacy of once-daily dosing of ziprasidone would also be helpful for clinicians.

\section{Acknowledgments}

Supported by NIMH MH-39415 and RR-000039. In the last 3 years, Dr. Nemeroff consulted to, served on the Speakers' Bureau and/or Board of Directors, has been a grant recipient, and/or owned equity in one or more of the following: Abbott Laboratories, Acadia Pharmaceuticals, AFSP, APIRE, AstraZeneca, BMC-JR LLC, Bristol-Myers-Squibb, CeNeRx, Corcept, Cypress Biosciences, Cyberonics, Eli Lilly, Forest Laboratories, George West Mental Health Foundation, GlaxoSmithKline, i3 DLN, Janssen Pharmaceutica, Lundbeck, NARSAD, NIMH, NFMH, NoveDel Pharma, Otsuka, Pfizer Pharmaceuticals, Quintiles, Reevax, UCB Pharma, Wyeth-Ayerst.

\section{References}

Allison DB, Mentore JL, Heo M, et al. 1999. Antipsychotic-induced weight gain: a comprehensive research synthesis. American Journal of Psychiatry, 156:1686-96.

American Psychiatric Association. 1992. Tardive dyskinesia: a task force report of the American Psychiatric Association. Washington, DC.

American Psychiatric Association. 2000. Diagnostic and statistical manual of mental disorders, 4 th ed, text revision. Washington, DC.

American Psychiatric Association. 2002. Practice guideline for the treatment of patients with bipolar disorder revision. American Journal of Psychiatry, 159(Suppl):1-50.

Ananth J, Burgoyne KS, Niz D, et al. 2004. Tardive dyskinesia in 2 patients treated with ziprasidone. Journal of Psychiatry and Neuroscience, 29:467-9.

Ananth J, Parameswaran S, Gunatilake S. 2004a. Side effects of atypical antipsychotic drugs. Current Pharmaceutical Design, 10:2219-29.

Ananth J, Parameswaran S, Gunatilake S, et al. 2004b. Neuroleptic malignant syndrome and atypical antipsychotic drugs. Journal of Clinical Psychiatry, 65:464-70.

Apseloff G, Mullet D, Wilner KD, et al. 2000. The effects of ziprasidone on steady-state lithium levels and renal clearance of lithium. British Journal of Clinical Pharmacology, 49(Suppl 1):61S-64S.

Arbuck DM. 2005. 12,800-mg ziprasidone overdose without significant ECG changes. General Hospital Psychiatry, 27:222-3.

Baldassano CF, Ballas C, Datto SM, et al. 2003. Ziprasidone-associated mania: a case series and review of the mechanism. Bipolar Disorders, $5: 72-5$.

Barnett MS. 2004. Ziprasidone monotherapy in pediatric bipolar disorder. Journal of Child and Adolescent, Psychopharmacology, 14:471-7.

Berkowitz A. 2003. Ziprasidone for dementia in elderly patients: case review. Journal of Psychiatric Practice, 9:469-73.

Borovicka MC, Bond LC, Gaughan KM. 2006. Ziprasidone- and lithiuminduced neuroleptic malignant syndrome. Annals of Pharmacotherapy, 40:139-42.

Bowden CL. 2005. Atypical antipsychotic augmentation of mood stabilizer therapy in bipolar disorder. Journal of Clinical Psychiatry, 3:12-19.

Bristol-Myers Squibb Company. 2006. Abilify prescribing information.

Caroff SN, Mann SC. 1993. Neuroleptic malignant syndrome. Medical Clinics of North America, 77:185-202.

Catalano G, Grace JW, Catalano MC, et al. 2005. Acute akathisia associated with quetiapine use. Psychosomatics, 46:291-301.

Chengappa KN, Suppes T, Berk M. 2004. Treatment of bipolar mania with atypical antipsychotics. Expert Review of Neurotherapeutics, 4 (6 Suppl 2):S17-25.

Cole SA, Saleem R, Shea WP, et al. 2005. Ziprasidone for agitation or psychosis in dementia: four cases. International Journal of Psychiatry in Medicine, 35:91-8. 
Daniel DG, Brooke S, Warrington LE, et al. 2004. IM ziprasidone in agitated patients with bipolar diagnoses. Presented at National Institute of Mental Health, New Clinical Drug Evaluation Unit, 44th Annual Meeting, Pheonix, AZ.

Daniel DG, Potkin SG, Reeves KR, et al. 2001. Intramuscular (IM) ziprasidone $20 \mathrm{mg}$ is effective in reducing acute agitation associated with psychosis: a double-blind, randomized trial. Psychopharmacology, 155:128-34.

Endicott J, Cohen J, Nee J, et al. 1981. Hamilton Depression Rating Scale. Extracted from regular and change versions of the schedule for affective disorders and schizophrenia. Archives of General Psychiatry, 38:98-103.

Endicott J, Spitzer RL. 1978. A diagnostic interview: the schedule for affective disorders and schizophrenia. Archives of General Psychiatry, 35:837-44.

Ernst CL, Goldberg JF. 2002. The reproductive safety profile of mood stabilizers, atypical antipsychotics, and broad-spectrum psychotropics. Journal of Clinical Psychiatry, 4:42-55.

Everson G, Lasseter KC, Anderson KE, et al. 2000. The pharmacokinetics of ziprasidone in subjects with normal and impaired hepatic function. British Journal of Clinical Pharmacology, 49(Suppl 1):21S-26S.

Gentile S. 2007. Extrapyramidal adverse events associated with atypical antipsychotic treatment of bipolar disorder. Journal of Clinical Psychopharmacology, 27(1):35-45.

Gentile S. 2006. Long-term treatment with atypical antipsychotics and the risk of weight gain: a literature analysis. Drug Safety, 29(4):303-19.

Ghaemi SN, Hsu DJ, Rosenquist KJ, et al. 2006. Extrapyramidal side effects with atypical neuroleptics in bipolar disorder. Progress in Neuro Psychopharmacology and Biological Psychiatry, 30:209-13.

Gill HS, DeVane CL, Risch SC. 1997. Extrapyramidal symptoms associated with cyclic antidepressant treatment: a review of the literature and consolidating hypotheses. Journal of Clinical Psychopharmacology, $17: 377-89$

Gomez-Criado MS, Bernardo M, Florez T, et al. 2005. Ziprasidone overdose: cases recorded in the database of Pfizer-Spain and literature review. Pharmacotherapy, 25:1660-5.

Gray NS. 2004. Ziprasidone-related neuroleptic malignant syndrome in a patient with Parkinson's disease: a diagnostic challenge. Human Psychopharmacology, 19:205-7.

Greco KE, Tune LE, Brown FW, et al. 2005. A retrospective study of the safety of intramuscular ziprasidone in agitated elderly patients. Journal of Clinical Psychiatry, 66:928-9.

Guy W. 1976. Early clinical drug evaluation manual. Washington, DC: United States Department of Health, Education, and Welfare.

Harrigan EP, Miceli JJ, Anziano R, et al. 2004. A randomized evaluation of the effects of six antipsychotic agents on QTc, in the absence and presence of metabolic inhibition. J Clin Psychopharmacol, 24:62-9.

Heinrich TW, Biblo LA, Schneider J. 2006. Torsades de pointes associated with ziprasidone. Psychosomatics, 47:264-8.

Hirsch SR, Kissling W, Bauml J, et al. 2002. A 28-week comparison of ziprasidone and haloperidol in outpatients with stable schizophrenia. Journal of Clinical Psychiatry, 63:516-23.

Isometsa ET, Henriksson MM, Aro HM, et al. 1994. Suicide in bipolar disorder in Finland. American Journal of Psychiatry, 151:1020-4.

Janssen. 2007. Risperdal prescribing information.

Kane JM, Smith JM. 1982. Tardive dyskinesia: prevalence and risk factors, 1959 to 1979. Archives of General Psychiatry, 39:473-81.

Kay SR, Fiszbein A, Opler LA. 1987. The positive and negative syndrome scale (PANSS) for schizophrenia. Schizophrenia Bulletin, 13:261-76.

Keck ME, Muller MB, Binder EB, et al. 2004. Ziprasidone-related tardive dyskinesia. American Journal of Psychiatry, 161:175-6.

Keck PE Jr, Pope HG Jr, Cohen BM, et al. 1989. Risk factors for neuroleptic malignant syndrome. A case-control study. Archives of General Psychiatry, 46:914-8.

Keck PE Jr, Versiani M, Potkin S, et al. 2003. Ziprasidone in the treatment of acute bipolar mania: a three-week, placebo-controlled, double-blind, randomized trial. American Journal of Psychiatry, 160:741-8.
Keck PE Jr, Warrington L, Potkin S, et al. 2004. Efficacy and safety of ziprasidone in bipolar disorder: short- and long-term data. 157th annual meeting of the American Psychiatric Association. New York, NY.

Kowatch RA, DelBello MP. 2006. Pediatric bipolar disorder: emerging diagnostic and treatment approaches. Child and Adolescent Psychiatric Clinics of North America, 15:73-108.

Leibold J, Patel V, Hasan RA. 2004. Neuroleptic malignant syndrome associated with ziprasidone in an adolescent. Clinical Therapeutics, 26:1105-8.

Lieberman JA, Stroup TS, McEvoy JP, et al. 2005. Effectiveness of antipsychotic drugs in patients with chronic schizophrenia. New England Journal of Medicine, 353:1209-23.

Levy WO, Robichaux-Keene NR, Nunez C. 2004. No significant QTc interval changes with high-dose ziprasidone: a case series. Journal of Psychiatric Practice, 10:227-32.

Lipinski JF Jr, Mallya G, Zimmerman P, Pope HG Jr. 1989. Fluoxetineinduced akathisia: clinical and theoretical implications. Journal of Clinical Psychiatry, 50:339-42.

Leso L, Schwartz TL. 2002. Ziprasidone treatment of delirium. Psychosomatics, 43:61-2.

Marken PA, Pies RW. 2006. Emerging treatments for bipolar disorder: safety and adverse effect profiles. Annals of Pharmacotherapy, 40:276-85.

Mason MN, Johnson CE, Piasecki M. 2005. Ziprasidone-induced acute dystonia. American Journal of Psychiatry, 162:625-6.

McIntyre RS, Konarski JZ. 2005. Tolerability profiles of atypical antipsychotics in the treatment of bipolar disorder. Journal of Clinical Psychiatry, 3:28-36.

McKenna K, Koren G, Tetelbaum M, et al. 2005. Pregnancy outcome of women using typical antipsychotic drugs: a prospective comparative study. Journal of Clinical Psychiatry, 66:444-9.

Mendhekar DN. 2005. Ziprasidone-induced tardive dyskinesia. Canadian Journal of Psychiatry Revue Canadienne de Psychiatrie, 50:567-8.

Miceli JJ, Wilner KD, Hansen RA, et al. 2000. Single- and multiple-dose pharmacokinetics of ziprasidone under non-fasting conditions in healthy male volunteers. British Journal of Clinical Pharmacology, 49 Suppl 1:5S-13S.

Michalopoulou PG, Lykouras L. 2006. Manic/hypomanic symptoms induced by atypical antipsychotics: a review of the reported cases. Progress in Neuro Psychopharmacology and Biological Psychiatry, 30:549-64.

Miodownik C, Hausmann M, Frolova K, et al. 2005. Lithium intoxication associated with intramuscular ziprasidone in schizoaffective patients. Clinical Neuropharmacology, 28:295-7.

Montgomery SA, Asberg M. 1979. A new depression scale designed to be sensitive to change. British Journal of Psychiatry, 134:382-9.

Mukherjee S, Rosen AM, Caracci G, et al. 1986. Persistent tardive dyskinesia in bipolar patients. Archives of General Psychiatry, 43:342-6.

Murty RG, Mistry SG, Chacko RC, et al. 2002. Neuroleptic Malignant Syndrome with ziprasidone. Journal of Clinical Psychopharmacology, 22:624-6.

Nasrallah HA, Churchill CM, Hamdan-Allan GA. 1988. Higher frequency of neuroleptic-induced dystonia in mania than in schizophrenia. American Journal of Psychiatry, 145:1455-6.

Nemeroff CB, Lieberman JA, Weiden PJ, et al. 2005. From clinical research to clinical practice: a 4-year review of ziprasidone. CNS Spectrums, 10:s1-20.

Newcomer JW. 2005. Second-generation (atypical) antipsychotics and metabolic effects: a comprehensive literature review. CNS Drugs, 19(Supp 1):1-93.

Ozen ME, Yumru M, Savas HA, et al. 2007. Neuroleptic malignant syndrome induced by ziprasidone on the second day of treatment. World Journal of Biological Psychiatry, 8:42-4.

Papakostas GI, Petersen TJ, Nierenberg AA, et al. 2004. Ziprasidone augmentation of selective serotonin reuptake inhibitors (SSRIs) for SSRI-resistant major depressive disorder. Journal of Clinical Psychiatry, 65:217-21. 
Patel NC, Keck PE Jr. 2006. Ziprasidone: efficacy and safety in patients with bipolar disorder. Expert Review of Neurotherapeutics, 6:1129-38.

Perlis RH, Welge JA, Vornik LA, et al. 2006. Atypical antipsychotics in the treatment of mania: a meta-analysis of randomized, placebo-controlled trials. Journal of Clinical Psychiatry, 67:509-16.

Pfizer. 2007. Geodon prescribing information.

Pierre JM. 2005. Extrapyramidal symptoms with atypical antipsychotics: incidence, prevention and management. Drug Safety, 28:191-208.

Potkin SG, Keck PE Jr, Segal S, et al. 2005. Ziprasidone in acute bipolar mania: a 21-day randomized, double-blind, placebo-controlled replication trial. Journal of Clinical Psychopharmacology, 25:301-10.

Potkin SG, Keck PE, Giller E, et al. 2004. Ziprasidone in bipolar mania: efficacy across patient subgroups. Presented at the 157th annual meeting of the American Psychiatric Association. New York, NY.

Preval H, Klotz SG, Southard R, et al. 2005. Rapid-acting IM ziprasidone in a psychiatric emergency service: a naturalistic study. General Hospital Psychiatry, 27:140-4.

Prieto T, Benabarre A, Bernardo M. 2005. The highest intentional ziprasidone overdose was not fatal. Acta Psychiatrica Scandinavica, 112:79-80.

Ramos AE, Shytle RD, Silver AA, et al. 2003. Ziprasidone-induced oculogyric crisis. Journal of the American Academy of Child and Adolescent Psychiatry, 42:1013-4.

Rosenquist KJ, Walker SS, Ghaemi SN. 2002. Tardive dyskinesia and ziprasidone. American Journal of Psychiatry, 159:1436.

Schmidt AW, Lebel LA, Howard HR Jr, et al. 2001. Ziprasidone: a novel antipsychotic agent with a unique human receptor binding profile. European Journal of Pharmacology, 425:197-201.

Simpson SG, Jamison KR. 1999. The risk of suicide in patients with bipolar disorders. Journal of Clinical Psychiatry, 2:53-6.

Sprague DA, Loewen PS, Raymond CB. 2004. Selection of atypical antipsychotics for the management of schizophrenia. Annals of Pharmacotherapy, 38(2):313-9.

Suppes T, Dennehy EB. 2001. Bipolar disorder algorithms. TIMA procedural manual. Dallas. 2001.
Suppes T, Dennehy EB, Hirschfeld RM, et al. 2005. The Texas implementation of medication algorithms: update to the algorithms for treatment of bipolar I disorder. Journal of Clinical Psychiatry, 66:870-86.

Swift RH, Harrigan EP, Cappelleri JC, et al. 2002. Validation of the behavioral activity rating scale (BARS): a novel measure of activity in agitated patients. Journal of Psychiatric Research, 36:87-95.

Vieta E. 2005. Bipolar mixed states and their treatment. Expert Review of Neurotherapeutics, 5:63-8.

Vornik LA, Hirschfeld RM. 2005. Bipolar disorder: quality of life and the impact of atypical antipsychotics. American Journal of Managed Care, 11(9 Suppl):S275-80.

Weiden PJ, Daniel DG, Simpson G, et al. 2003. Improvement in indices of health status in outpatients with schizophrenia switched to ziprasidone. Journal of Clinical Psychopharmacology, 23:595-600.

Weinstein SK, Adler CM, Strakowski SM. 2006. Ziprasidone-induced acute dystonic reactions in patients with bipolar disorder. Journal of Clinical Psychiatry, 67:327-8.

Weisler R, Dunn J, English P. 2003. Ziprasidone in adjunctive treatment of acute bipolar mania: randomized, double-blind, placebo-controlled trial. 55th Institute on Psychiatric Services Meeting. Boston, MA.

Weisler R, Warrington L, Dunn J, et al. 2004. Adjunctive ziprasidone in bipolar mania: short- and long-term data. 157th annual meeting of the American Psychiatric Association. New York, NY.

Wirshing WC. 2001. Movement disorders associated with neuroleptic treatment. Journal of Clinical Psychiatry, 21:15-8.

Yang SH, McNeely MJ. 2002. Rhabdomyolysis, pancreatitis, and hyperglycemia with ziprasidone. American Journal of Psychiatry, 159:1435.

Young CC, Lujan E. 2004. Intravenous ziprasidone for treatment of delirium in the intensive care unit. Anesthesiology, 101(3):794-5.

Young RC, Biggs JT, Ziegler VE, et al. 1978. A rating scale for mania: reliability, validity and sensitivity. British Journal of Psychiatry, 133:429-35. 